\title{
SIMPLICIDAD DE DIOS Y PLURALIDAD DE ATRIBUTOS DIVINOS SEGÚN FRAY LUIS DE LEÓN
}

Santiago Orrego*

RESUMO - A atribuição das idéias platônicas à mente de Deus gera um problema, a saber: como falar em "atributos divinos" sem introduzir uma multiplicidade à substância simples divina? A partir desse problema, o presente artigo tem por finalidade apresentar como Luis de Léon se posiciona entre Tomás de Aquino e João Duns Scotus.

PALAVRAS-CHAVE - Atributos divinos. Tomás de Aquino. João Duns Scotus.
ABSTRACT - The platonic ideas attribution into God's mind creates a problem, namely: how to speak about "divine attributes" without put multiplicity into the divine simple substance? From this problem, this paper aims to show how Luis de Léon is between Thomas Aquinas and John Duns Scotus.

KEY WORDS - Divine attributes. Thomas Aquinas. John Duns Scotus.

\section{Platonismo y escolástica en Fray Luis de León}

Una de las tareas más arduas y más debatidas que surgieron en el pensamiento filosófico occidental cuando se buscó su inserción en la tradición religiosa judeo-cristiana fue la de conciliar la doctrina de la absoluta simplicidad de Dios con la pluralidad de los atributos y nombres divinos - sabiduría, justicia, bondad, belleza, etc. Una dificultad análoga se presentó al querer situar la multitud de las Ideas platónicas en la mente divina, sobre todo desde el momento en que se afirmó que las Ideas se identifican con la esencia misma de Dios. Creo que ambas cuestiones están estrechamente vinculadas. Más aun, como intento

* Pontificia Universidad Católica de Chile. Este estudio es resultado parcial de un proyecto de investigación financiado por el programa "Fondecyt" del Gobierno de Chile (proyecto $n^{\circ} 11.070 .028$ ), al que dirijo mi agradecimiento. Se titula: "Metafísica, ética y mística de las Ideas divinas en la síntesis platónica, humanista y escolástica de Fray Luis de León en el contexto de la Escuela de Salamanca del siglo XVI". 
probar en otro lugar, ${ }^{1}$ estimo que la pervivencia, en el pensamiento escolástico, de lo fundamental de la doctrina platónica de las Ideas no se pone verdaderamente en juego cuando en él se trata explícitamente de la cuestión de Ideis ${ }^{2}$ sino cuando se acepta o se rechaza, primero, que la pluralidad de los atributos divinos es en cierto modo objetiva y no una mera ficción de nuestra mente finita; $y$, segundo, que los atributos divinos describen a Dios en sí mismo - es decir, no son sólo "denominaciones extrínsecas" -, aunque sea imperfectísimamente. ${ }^{3}$ Ésta tesis requeriría, obviamente, una justificación pormenorizada y uno de los elementos de esa justificación tendría que ser nada menos que determinar qué es "lo fundamental de la doctrina platónica de las Ideas".

Por ahora, para efectos de claridad expositiva, permítaseme afirmar que lo esencial del platonismo no radica en la afirmación de la existencia de un mundo que replica inteligiblemente los objetos o especies del mundo físico, sino en la existencia de "realidades en sí", plenas, eternas y absolutamente necesarias, como "lo justo en sí", "lo bello en sí", "el bien en sí", "lo igual en sí", que no tienen una correspondencia perfecta en el mundo físico, sino que son imitadas o participadas en él imperfectamente, de modo derivado, como de una fuente. Y es ésta participación lo que hace del mundo algo inteligible, un "cosmos" y no un "caos"; es la semejanza con esas realidades eternas lo que hace posible contemplar el mundo sub specie aeternitatis. Por eso, para la pervivencia consciente o inconsciente del platonismo, no es tan relevante la afirmación de que Dios conoce desde la eternidad las cosas que crea, como la aceptación de que existen aquellas realidades en sí y que éstas se relacionan del modo dicho con el mundo físico.

Ahora bien, en la tradición judeo-cristiana, sólo puede admitirse la existencia de tales realidades en la medida en que, de algún modo, se

1 ORREGO, S. "Recepción y transformación medieval de la doctrina platónica de las Ideas", en preparación. En ese trabajo procuro fundamentar las interpretaciones sobre la filosofía platónica y medieval presupuestas en este artículo, y que sintetizo muy sumariamente en los siguientes párrafos.

2 Dos exposiciones e interpretaciones globales sobre las cuestión de Ideis en la Edad Media pueden verse en UÑA JUÁREZ. 1990-91, y en HOENEN. 1997.

3 Ésta tesis puede verse apoyada, además, en el hecho de que se haya incluido el tema de los atributos divinos en una excelente monografía sobre las doctrina de las Ideas en Tomás de Aquino: BOLAND. 1996. Reproduzco aquí un significativo texto de Tomás de Aquino, In I Sent. d. 2 q. 2 a. 2, relevante para comprender la perspectiva global del presente artículo: "Unde ipse [sc. Deus] est exemplaris forma rerum, non tantum quantum ad ea quae sunt in sapientia sua, scilicet secundum rationes ideales, sed etiam quantum ad ea quae sunt in natura sua, scilicet attributa". Salvo que indique lo contrario, cito las obras de santo Tomás por las ediciones on-line, en http://www.corpusthomisticum.org, preparadas por Enrique Alarcón (Universidad de Navarra). El texto on-line de In I Sententiarum es el de la edición de Parma de 1856. 
las identifica con Dios mismo, pues en esa tradición sólo Dios es eterno, increado y absolutamente necesario, mientras que todo lo demás debe afirmarse como radicalmente dependiente de la acción libre y creadora de Dios. Por eso, las Ideas platónicas, en el sentido descrito, sólo pueden aceptarse como perfecciones o atributos de Dios mismo.

La dificultad de esta doctrina es evidente: según ella, los múltiples atributos divinos serían aspectos o expresiones parciales de una misma esencia divina. Ahora bien, ¿cómo algo que es absolutamente simple puede tener diversos aspectos o ser expresado parcialmente? La crítica de Ockham a esta doctrina defendida por sus antecesores del siglo XIII y XIV se centró certeramente en este punto: lo que es absolutamente simple no puede tener una pluralidad de aspectos ni expresiones parciales de lo que ello es en sí mismo. ${ }^{4}$ Por eso, la esencia divina no es imitable y se abre un abismo entre ella y la radical contingencia de las criaturas, abismo que no puede ser salvado ni por la analogía ni por la participación. Estimo que éste es el momento preciso, de enormes consecuencias en todo el sistema del pensamiento, en que una parte importante de la tradición escolástica se aparta realmente del platonismo. Y después de este momento, los pensadores escolásticos ya no podrán repetir sin más las tesis de Tomás de Aquino, Buenaventura, Gante o Escoto, sino que, si quieren volver a ellas, deberán hacer frente a las objeciones de los nominales y de la filosofía crítica del siglo XIV, lo mismo en ésta que en muchas otras cuestiones. Esto obligará a un gran esfuerzo de especulación, de desarrollos metafísicos y de distinción conceptual, y hace de la llamada "segunda Escolástica" un movimiento intelectual que de ningún modo puede considerarse mera repetición ni simple desarrollo lineal de sus fuentes inspiradoras del siglo XIII.

En este paisaje se inscribe la figura del maestro y poeta Fray Luis de León, sobre quién aun se discute en qué medida fue platónico o escolástico tomista. ${ }^{5}$ Por lo expuesto en los párrafos anteriores, puede

4 OCKHAM, G. Ord. I, d. 2, q. 2 (Op. theol. II, p. 67): "Secundo patet quod non est bene dictum quod attributa distinguuntur quia intellectus non potest totaliter divinam essentiam comprehendere et ideo particulatim eam apprehendit, quia essentia divina non est sic particulatim apprehensibilis, sed vel totaliter apprehenditur vel nihil". Podríamos añadir: "Non totaliter; ergo, nihil": no hay analogía en el sentido clásico.

5 Para una síntesis del estado de esta cuestión, me permito remitir a ORREGO, S. "Presentación: texto, contexto y criterios de edición". En: DE LEÓN, L. Dios y su imagen en el hombre. Lecciones inéditas sobre el libro I de las Sentencias (1570), edición de Santiago Orrego. Pamplona: Eunsa, 2008, 18-20. En este libro se encuentran las enseñanzas de Fray Luis que serán objeto principal del presente trabajo, por lo que amerita aquí una breve explicación. Recoge las lecciones de Fray Luis de León y de su sustituto, Agustín de Mendiola, en la cátedra "de Durando" de la Universidad de Salamanca del curso 1569-70, a partir del único manuscrito en que se han conservado (Coimbra, Biblioteca Geral da Universidade, Cód. 1834, ff. 4r-114v), 
verse que el estudio de su doctrina sobre los atributos divinos - bondad, unidad, belleza, sabiduría, justicia, etc. -, además del interés filosófico que puede tener en sí misma, es una pieza clave para poder determinar si es ambas cosas, sin contradicción, o si hay varios "Luises de León": el teólogo escolástico, el místico, el humanista... En este estudio me centraré preferentemente en la exposición que hizo de este tema en sus lecciones en la Universidad de Salamanca del curso de 1569-70, donde confronta su pensamiento especialmente con el de Juan Duns Escoto. Defenderé que lo más relevante de su pensamiento sale a la luz al clarificar cuáles pudieron ser las verdaderas razones de que se distanciara del Sutil, a pesar de que sus maestros en Salamanca habían defendido la conformidad de Tomás de Aquino y Duns Escoto en la cuestión de los atributos divinos. Al final, aludiré a un pasaje clave de su más célebre obra castellana, De los nombres de Cristo, que revela una perfecta congruencia con su doctrina académica sobre los atributos divinos, con el fin de ilustrar, en la medida en que el espacio lo permite, la afinidad de sus doctrinas en sus diferentes tipos de escritos.

\section{Noción propia de "atributo divino": perfecciones creadas y perfecciones increadas}

Trata de la unidad de Dios y de la pluralidad de sus atributos en su "lugar natural": la distinción 2 del primer libro de las Sentencias, donde Durando propone cuatro cuestiones: primera, si Dios es uno sólo; segunda, si hay en él una pluralidad de atributos; tercera, si algún entendimiento puede concebir la pluralidad de los atributos divinos sin referencia a las criaturas, es decir, considerando a Dios sólo en sí mismo; y cuarta, si es compatible la unidad de la esencia con la pluralidad de las personas divinas. ${ }^{6}$ Las tres primeras son relevantes para el tema de este estudio. La primera, en rigor, no trata del atributo divino de la "unidad" - el "unum" trascendental - sino de la unicidad de Dios, pero el primero de

con traducción castellana al frente. Los textos que aquí se analizarán corresponden a las lecciones del propio Fray Luis, recogidas in situ por uno de sus alumnos, con las imperfecciones propias de unos apuntes de clase, pero fiables en lo sustancial. Correspondía al catedrático "de Durando" explicar según el orden del Comentario de Durando de Saint Pourçain (1275-1334) a los Libri Sententiarum de Pedro Lombardo. Como ya era habitual en Salamanca, Fray Luis casi siempre se limita a señalar las cuestiones y las conclusiones de Durando, para seguir luego independientemente. Después de la d. 4, abandona derechamente el texto de Durando y explica según el orden de la Summa theologiae de Tomás de Aquino.

6 DURANDO (Durand de Saint Pourçain). In Petri Lombardi Sententias Theologicas Commentariorum libri IIII. Venetiis: Ex Typographia Guerræa, 1571 (Edición facsímil de Ridgewood, New Jersey (EE.UU.): The Gregg Press Incorporated, 1964), 16va-20va. 
los argumentos desarrollados por Fray Luis para probar que sólo existe un Dios pone las bases para las dos siguientes cuestiones y es fundamental para apreciar su aproximación platónica al tema.

Fray Luis remite a los muchos argumentos de Tomás de Aquino en Contra gentiles I, $42,{ }^{7}$ y señala que sólo desarrollará dos - aunque, de hecho, desarrolla cuatro. El primero de los argumentos de Fray Luis reza así:

Dios, según la común concepción del alma, se entiende como sumamente bueno y sumamente perfecto, y por esencia bueno y perfecto, esto es, como aquello por cuya participación las demás cosas son buenas y perfectas. Ahora bien, es imposible que haya dos cosas sumamente buenas y perfectas, pues se llama sumamente bueno a lo que excede y supera a todo; luego. ${ }^{8}$

Si se compara esta formulación con la de Tomás en el texto aludido por Fray Luis, salta a la vista cómo en la del agustino se enfatiza la concepción platónica, con elementos que, por otro lado, también se encuentra frecuentemente en el Aquinate. Primero, mientras Tomás supone como algo ya probado - y que debía ser probado -, en el capítulo anterior de Contra gentes I, que Dios es lo máximamente perfecto, Fray Luis parece estimar como suficiente que esa nota está ya incluida en la idea de Dios, en la "común concepción del alma". La afirmación de que Dios es bueno y perfecto "por esencia" y que todo las demás cosas buenas y perfectas lo son "por participación suya", no está en el texto de Tomás, y es significativo que Fray Luis, justo aquí, lo traiga a colación, pues esta concepción metafísica platónica se pondrá en juego, sobre todo, en la resolución de la tercera pregunta formulada por Durando, como espero mostrar.

El segundo argumento complementa el anterior y sitúa el tema en la perspectiva de la causalidad: la razón por la que debemos atribuir toda perfección a Dios, es que Él es causa de todas. Dice:

Además, si hubiera muchos dioses, necesariamente diferirían entre sí por alguna perfección y, por consiguiente, a uno le faltaría algo del bien y de la perfección que le corresponde al otro, lo cual no puede darse en la naturaleza de Dios, que es la causa de todas las cosas y perfecciones. ${ }^{9}$

Sigue esta línea al desarrollar la segunda de las cuestiones propuestas por Durando: "Si los atributos divinos difieren de algún modo por la misma naturaleza de la cosa (ex ipsa natura rei) con independencia de

7 Cf. TOMÁS DE AOUINO. Summa contra Gentiles I, c. 42. El texto on-line (http:// www.corpusthomisticum.org) de la Summa contra Genitles es el de la edición leonina.

8 DE LEÓN, L. Op. cit, p. 74-5.

9 DE LEÓN, L. Ibid. 
toda operación del entendimiento". ${ }^{10}$ Para resolver esta pregunta, dice Fray Luis, antes que nada debe explicarse qué son los atributos divinos, para lo cual se remonta al siguiente principio según el cual en Dios se encuentran todas las perfecciones de todas las criaturas existentes o sólo posibles, pasadas, presentes y futuras, porque - prosigue en tono platónico - "Dios es la suma perfección a partir de la cual, como de una fuente primera, deriva todo lo bueno y lo perfecto". ${ }^{11}$ Mas la participación se explica o fundamenta a partir de la causalidad divina. En efecto, porque Dios es la causa de todas las cosas, y es necesario que todo lo que hay de bondad y perfección en el efecto se encuentre de un modo máximo en la causa, se concluye que en Dios están las perfecciones de todas las cosas. ${ }^{12}$

Fray Luis refiere varias autoridades en apoyo de esta tesis: la Sagrada Escritura (Sant 1, 17), Juan Damasceno, Dionisio Areopagita y Tomás de Aquino, comprendidos de un modo concordante, como puede verse también en todo el resto de la obra de Fray Luis. Puede extrañar esto a quienes aún siguen viendo a Tomás de Aquino simplemente como el "Aristóteles cristiano", idea todavía arraigada incluso en personas con cultura filosófica y afianzada durante largo tiempo por la simple expresión "filosofía aristotélico-tomista". Aparte del hecho de que esa expresión está ya casi en desuso y de que muchas investigaciones de las últimas décadas han establecido con solidez que, en el pensamiento de Tomás, los elementos platónicos o neoplatónicos son, por lo menos, tan fundamentales como los aristotélicos, lo relevante es que los maestros de Salamanca veían en Tomás, sobre todo, al gran sintetizador de las enseñanzas milenarias de los Padres de la Iglesia. ${ }^{13}$

Para precisar la noción de "atributo" divino, prosigue Fray Luis con la distinción tradicional entre perfecciones absolutas (simpliciter) y

10 DURANDO. Op. cit., 17 rb; DE LEÓN, L. Op. cit., p. 78-79.

11 DE LEÓN, L. Ibid.

12 Cf. DE LEÓN, L. Ibid.

13 Sirvan como prueba dos testimonios: uno, del fundador de la Escuela de Salamanca, Francisco de Vitoria, y otro, de uno de sus últimos representantes, Domingo Báñez. Dice Vitoria: "Laudare ergo potius, quam calumniari, debemus factum recentiorum doctorum, qui nobis ex antiquis doctoribus tradiderunt per genera et species materias omnes, et inter omnes sine dubio Sanctus Thomas maiori ordine procedit, si ipsum inter recentiores computemus, quem inter antiquos scilicet, Augustinum et Hieronymum, puto reponendum et ad illos comparandum, non quod eum maiorem aut aequalem illis dicam, sed profecto studiosissimum et diligentissimum collectorem sacrae scripturae et sacrorum doctorum". VITORIA, F. Commentaria in Primam Partem Divi Thomae, q. 1, a. 1 (Santander, Biblioteca Menéndez Pelayo, Ms. 18, f. 10v; editado en POZO. 1962, vol. I, p. 45). Y Báñez: "Ego statui per omnia et in omnibus sequi doctrinam Sancti Thomae, quoniam ipse secutus est semper doctrinam Sanctorum Patrum". BÁÑEZ, D. Commentaria in Secundam Secundae, q. 24, a. 6 (citado en BELTRÁN DE HEREDIA. 1972, p. 160). 
restringidas (secundum quid). Las primeras son aquellas que, en su índole propia, sólo incluyen perfección sin mezcla alguna de imperfección, por lo que también son llamadas "perfecciones puras", como la sabiduría, la verdad, la bondad y otras. Las segundas son aquellas que, en su noción o índole propia, incluyen algo imperfecto y son, por ello, impuras, como "humanidad" o "equineidad". ${ }^{14}$ Se debe afirmar que en Dios están ambos géneros de perfección, pero de modo distinto: las perfecciones restringidas no están en Dios "formalmente", sino "de modo eminente", esto es, de una manera más elevada que consiste en suprimir de ellas todo lo que hay de imperfección. Dice Fray Luis, de manera expresiva: "En efecto, en Dios está la perfección humana, pero no al modo humano, sino al modo divino, esto es, sin la materia, la composición y las demás imperfecciones". Las perfecciones puras, en cambio, puesto que no implican imperfección, están en Dios formalmente: se pueden predicar de Dios; "y a estas perfecciones que existen en Dios formalmente, los teólogos las llaman atributos divinos". ${ }^{15}$

\section{La tensión entre la simplicidad divina y la pluralidad de sus atributos}

Inadvertidamente, ya se ha tomado aquí una opción intelectual relevante y difícil, de la cual Fray Luis era sin duda consciente, a saber, la de afirmar que los mencionados atributos se predican "formalmente" de Dios. Según una vertiente significativa del pensamiento neoplatónico cristiano, como el del pseudo Dionisio, nada menos, o el de su seguidor Juan Escoto Eriúgena, es por lo menos discutible que los múltiples "nombres" o atributos que se predican de Dios designen algo que sea propiamente identificable con la esencia divina o, si se quiere, con la Divinidad misma. En efecto, según este pensamiento, de Dios se pueden predicar sus efectos; y el bien en sí, la unidad en sí, la vida en sí, se describen como creadas por Dios, estando Dios mismo siempre realmente más allá de ellas - y, al mismo tiempo, en ellas y en todo -, y sólo en razón de esto - de la legitimidad de predicar el efecto de la causa mediante la cópula "es", de nombrar a la causa con el nombre de sus efectos -, se puede decir, como hace la Escritura, que Dios es bueno o el bien en sí, que Dios es viviente o la vida en sí, etc. ${ }^{16}$ Se enfatiza, es cierto, que todos los

14 DE LEÓN, F. Op. cit., p. 78-81.

15 DE LEÓN, F. Op. cit., p. 80-1.

16 Cf. PSEUDO DIONISIO AREOPAGITA. Los nombres de Dios c. 11, 953b-953c: "Una vez por carta me preguntaste qué significa 'ser por sí', 'vida por sí', 'sabiduría por sí'. Dices que no aciertas a entender por qué a veces llamo a Dios 'vida por sí' y otras veces 'autor de la vida por sí' (...). Ciertamente, repitiendo ahora lo que he dicho miles de veces, no implica contradicción alguna el decir que Dios es 'poder por sí', 
efectos de Dios preexisten en Él de modo unido, simple y eminente; pero esto es lo mismo que acaba de decir Fray Luis - siguiendo la tradición escolástica - acerca de las perfecciones restringidas o impuras, las cuales, no obstante su preexistencia en Dios, no se pueden identificar con Dios. Afirma el pseudo Dionisio que predicar de Dios las formas espirituales Inteligencia, Sabiduría, Vida - es tan inadecuado como predicar de Él las materiales. ${ }^{17}$ Ahora bien: la expresión, de raíz aristotélica, según la cual las perfecciones puras están "formalmente" en Dios, busca justamente declarar de modo inequívoco la pertenencia de esas perfecciones que se predican de Dios a la esencia misma de Dios mismo.

La propuesta del pseudo Dionisio y de Escoto Eriúgena es apta para salvar la absoluta simplicidad, trascendencia e incognoscibilidad de Dios en sí mismo: todo esto es aceptado y aun remarcado por Fray Luis, como se verá. Sin embargo, en Fray Luis jamás se encontrará, como sí ocurre en el pseudo Dionisio, una negación directa de esas perfecciones respecto de Dios, salvo cuando cita al pseudo Dionisio, para reinterpretarlo en sentido tomista: aunque podemos afirmar con propiedad y "formalmente" que Dios es el bien, la belleza, la justicia, etc., siempre queda más allá de nuestra comprensión qué sean estas perfecciones en Dios y cómo se realizan en Él de modo infinito y simple. ${ }^{18}$ Lo que Platón llamara Ideas, entendidas en el sentido indicado al comienzo de este trabajo, reinterpretadas en parte de la tradición judeo-cristiana como "atributos" divinos, no se "atribuyen" a Dios sólo porque Él es su causa ni por referencia a algo distinto de Dios mismo, sino porque propia y positivamente dicen algo verdadero acerca de Dios en sí mismo. Esto es lo que significa predicar "formalmente": puesto que la forma o lo formal en algo es un constitutivo intrínseco -la "forma" aristotélica se opone polémicamente a la Idea platónica trascendente-, se elimina la ambigüedad de la dialéctica del pseudo Dionisio: según Fray Luis, los múltiples atributos divinos se

\footnotetext{
'vida por sí', y decir también que es 'creador de la vida por sí' y de la 'paz por sí' y del 'poder por sí'. En los primeros casos se habla de Dios a partir de los seres, y principalmente de los seres fundamentales, que se predican de Dios en cuanto que es Causa de todos los seres, mientras que las segundas expresiones se le atribuyen en cuanto que Él es supraesencial a todo ser, aún a los más fundamentales".

17 Cf. PSEUDO DIONISIO AREOPAGITA. La jerarquía celeste, 140c-140d: "Éstas formas sagradas [sc. 'Inteligencia', 'Esencia', 'Luz', 'Vida', etc.] ciertamente muestran más reverencia y parecen superiores a las representaciones materiales. No son, sin embargo, menos deficientes que las otras con respecto a la Deidad, que está más allá de cualquier manifestación del ser y de la vida". Las cursivas son mías.

18 Cf. DE LEÓN, F. Op. cit., p. 82: “[...] ipsa ratio divinae bonitatis idem est quam ipsa ratio sapientiae et potentiae divinae, quia omnium istarum rerum est una ratio simplex, scilicet, ipsamet ratio divinae essentiae. Unde recte dicit Divus Dionysius quod Deus potius est appellandus super sapientiam quam sapiens, et super bonitatem quam bonus".
} 
identifican con la divinidad misma y pueden predicarse de ella en razón de esta identidad.

Esta concepción tiene la virtualidad de hacer de Dios algo comunicable y revelable; más aun, permite afirmar que, en cierto modo, Dios ya ha comunicado sus perfecciones y se ha revelado en la creación y mediante el leguaje de la Revelación sobrenatural. Esta concepción hace posible que haya un lenguaje divino-humano, lo que tiene importantes resonancias en el pensamiento de Fray Luis: en su metafísica, en su cristología, en su fundamentación de la ética, en su teoría del nombre, en su mística. En efecto, la divinidad, en cuanto tal, no es comunicable - en el orden natural -, pues Dios no puede crear otro Dios ni una sustancia de naturaleza divina. Pero, según esta concepción, la divinidad sí es comunicable en cuanto que es el bien, la belleza, el poder, la sabiduría, la vida, el ser... Pero esta concepción encierra también una dificultad importante, tal vez insoluble. Si se acepta que el bien, el poder, la sabiduría, la justicia y la misericordia, la inteligencia y la voluntad, poseen índoles o naturalezas - formalitates, rationes - diversas, ¿cómo se puede afirmar que están realmente en Dios, sin afirmar a la vez que en Dios hay multiplicidad, una pluralidad anterior a la consideración de nuestra mente limitada e independiente de ella?

\section{Confrontación con la doctrina de Escoto}

Es natural que sea ésta la siguiente cuestión planteada por Fray Luis: "Si los atributos divinos de algún modo difieren entre sí por la misma naturaleza de la cosa (ex natura rei) con independencia de toda operación del entendimiento". ${ }^{19}$ La formulación de la cuestión ya indica quién será el referente polémico: Juan Duns Escoto. No obstante, debe destacarse también que los maestros de Fray Luis en Salamanca, como Domingo de Soto y Melchor Cano, se sirvieron del lenguaje escotista para formular un nuevo sentido de "distinción real" - al tiempo que reprocharon al Sutil utilizar en muchas ocasiones la expresión ex natura rei para distinciones que sólo pueden considerarse de razón. ${ }^{20}$

Tal vez no esté de más reiterar que Fray Luis acepta que los múltiples atributos divinos están formalmente en Dios antes de cualquier operación de nuestro entendimiento; también Escoto afirma que, en Dios, se identifiquen realmente entre sí, de modo que no rompen la absoluta simplicidad divina. Lo que discute Fray Luis en este punto es si se

${ }_{19}$ DE LEÓN, F. Op. cit., p. 78-79. Estimo que la expresión típicamente escotista ex natura rei también puede traducirse, al menos en este contexto, como "por parte de la realidad en sí misma".

20 Cf. ORREGO. 2004, p. 189-204; 246-253. 
distinguen formalmente antes de la operación del entendimiento, ${ }^{21}$ lo que Escoto acepta y Fray Luis niega. Es especialmente difícil comprender y exponer bien la posición de Escoto, sobre todo porque este punto depende totalmente de su peculiar concepción de la distinctio formalis ex natura rei, objeto de controversias hasta el día de hoy y desde los primeros comentadores del Sutil; ${ }^{22}$ como depende también de la compleja teoría de la predicación de Duns Escoto. Sin embargo, no es relevante, para el presente trabajo, determinar en qué medida Fray Luis comprende bien la posición de Escoto o si le hace justicia, sino más bien cómo perfila su propia posición en su discusión con ella. En este breve espacio, no es posible presentar un análisis de todos los argumentos que Fray Luis expone a favor y en contra. Me detendré sólo en uno, especialmente significativo.

Primero, expone la posición de Escoto: "En esta cuestión, Escoto, en In I Sent. d. 8, q. 3, sostiene que sí: que se distinguen antes de la operación del entendimiento, pero no realmente como dos cosas, sino formalmente, porque poseen diversas definiciones o índoles (rationes)". ${ }^{23}$ Ya es de notar, en esta formulación de la tesis de Escoto, que no dice que Escoto niegue toda distinción real entre los atributos, sino sólo un modo de distinción real, a saber, la distinción real tanquam res a re o inter rem et rem o, en la formulación de Fray Luis, realiter sicut duae res. ${ }^{24}$ Con esto, deja abierta la posibilidad de interpretar la "distinción formal" como una forma menor de distinción real, que, por ello, sería incompatible con la simplicidad divina. Creo que éste no es el único motivo posible del rechazo de Fray Luis de la tesis de Escoto. No obstante, la pregunta acerca de si la "distinción

${ }^{21}$ La formulación precisa de Escoto en la Lectura es ésta: "Sic igitur arguitur contra praedictam opinionem secundum quod doctor ille tenet eam, et etiam contra aliud quod alii addunt, quod sunt in essentia formaliter ante actum intellectus sed non distinguuntur ante operationem intellectus". DUNS ESCOTO. Lect. I, d. 8, q. 4, n. 164 (Vat. XVII, p. 58). Propone luego su conclusión: "Sunt igitur diversae rationes formaliter, et etiam ante actum intellectus, quia quaelibet, ut probatum est, est ex natura rei, et tamen una non est formaliter alia; et hoc simul, sine compositione". Ibid., n. 176 (Vat. XVII, p. 63). Los textos paralelos de la Ordinatio son sustancialmente equivalentes.

22 Este tema puede verse tratado en NOONE. 1999. El autor de este artículo pretende mostrar que los primeros intérpretes de Escoto comprendieron la mencionada distinción como una distinción media entre la real y la de razón, y que esto habría sido causa de posteriores incomprensiones, hasta Leibniz.

23 DE LEÓN, F. Op. cit., p. 80-81. En realidad, aunque Escoto menciona ahí este tema, lo trata expresamente en la q. 4., tanto de la Lectura como de la Ordinatio.

${ }^{24}$ Como ya queda dicho, los maestros de Fray Luis de León en Salamanca - Domingo de Soto y Melchor Cano, principalmente - se esforzaron por formular un sentido nuevo de distinción propiamente real, distinto de la distinción inter rem et rem, para dar cuenta de los problemas relativos a la naturaleza y el supuesto y la esencia y la existencia, y para ello se aproximaron a las formulaciones de Escoto. Cf. ORREGO, S. loc. cit. 
formal" que propone Escoto es real o de razón es un inicio imprescindible para juzgar la posición del Doctor Sutil. En efecto, siguiendo a Durando y a su maestro Domingo de Soto, entre muchos otros, Fray Luis sostiene que no hay ninguna distinción media entre la real y la de razón. ${ }^{25}$ Ahora bien: puesto que la distinción de razón, por su misma definición, nace de la operación del entendimiento, es necesario afirmar que toda distinción previa a la operación del entendimiento es una distinción real. Por eso, la descripción de una distinción como formalis ex natura rei aún podría interpretarse en el sentido de una distinción de razón; pero si a esto se añade ante operationem intellectus, esa posibilidad queda cerrada.

Por este motivo, puede parecer que la posición de Escoto implicaría o bien que se introduce una suerte de composición real en Dios - lo que sería la consecuencia más evidente, pero expresamente rechazada por Escoto - o bien que, cuando se predican de Dios sus atributos o perfecciones puras, no se manifiesta la misma naturaleza divina ni algo que pertenece propiamente a Dios en el sentido pretendido por la escuela tomista, sino algo en cierto modo extrínseco a ella. En este segundo caso, sería necesario clarificar qué significa, en el sistema escotista, que algo se predique "formalmente" de Dios y cuál es el estatuto ontológico que le corresponde a las formalitates independientemente del intelecto. Pero Fray Luis no entra en estas cuestiones de exégesis, sino que expone directamente algunos de los argumentos del Sutil para luego refutarlos. El primero en favor de la tesis de Escoto es el siguiente:

La bondad y la sabiduría, por ejemplo, consideradas en general (in communi), se distinguen por la naturaleza de la cosa, porque poseen diversas índoles (rationes), como es claro. Luego, la bondad y la sabiduría de Dios se distinguen absolutamente por la naturaleza de la cosa. Se prueba la consecuencia, porque la bondad de Dios no posee otra definición que la de la bondad dicha en sentido absoluto, por más que la bondad de Dios sea infinita mientras que la bondad absoluta abstrae de ambas cosas, a saber, de lo finito y de lo infinito. Y es algo cierto que la infinitud no varía la índole de algo, pues las líneas finita e infinita no difieren en especie. ${ }^{26}$

${ }_{25}$ DE LEÓN, F. Op. cit., 78-9; DURANDO. Op. cit., d. 2, q. 2, 17 va; DE SOTO, D. In Porphyrii Isagogen ac Aristotelis Categorias (...) absolutissima commentaria. Venecia, 1587, p. 41-42.

${ }^{26}$ DE LEÓN, F. Op. cit., p. 80-81. Ensayo aquí una traducción distinta de la mía en la edición citada y, en parte, la corrijo. La principal variación está en la forma de traducir ratio, que, a mi juicio, en muchos contextos, es uno de los términos escolásticos más difíciles de verter al español sin asumir una interpretación discutible. En el lenguaje escolástico, el término ratio, cuando no se refiere a la facultad intelectiva humana, tiene un matiz mucho más objetivo que el que puede tener "razón" para nosotros. Así, por ejemplo, una expresión, extraña en castellano corriente, como "razón de sabiduría", posiblemente será comprendida por el lector hispano como un concepto - "concepto formal", psicológico - como algo producido por la razón como facultad subjetiva, de manera que la "razón de sabiduría" podría ser distinta para 
El argumento parte de un hecho manifiesto: lo que entendemos por "bondad" o "sabiduría" de modo general son índoles (rationes) distintas, lo que se manifiesta en sus definiciones. Ahora bien, la índole de la sabiduría de Dios no es distinta de la índole de la sabiduría en general. Luego, si se distinguen en general ex natura rei, también se distinguen en Dios ex natura rei. Además, se descarta el único motivo por el que se podría pensar que en Dios poseen una índole distinta, a saber, porque en Dios son infinitas, pues el modo de la infinitud no parece variar la índole de lo que se dice que es infinito, como es claro en el ejemplo de la línea, cuya definición es la misma para una línea finita y para una infinita. ${ }^{27}$

En este último punto incide la crítica de Fray Luis, para lo que introduce una distinción entre lo que es infinito sólo dentro de su género, y lo que es infinito "en la índole de ente y absolutamente". La del primer tipo es una infinitud en sentido restringido; ${ }^{28}$ es decir, no es propiamente infinitud, y, según Fray Luis, este tipo de infinitud no hace variar la índole (ratio). En cambio, "lo infinito del segundo modo varía la índole, pues aquello que es infinito de este modo posee todas las índoles del ente". ${ }^{29}$ Este texto es decisivo y muestra la profunda filiación tomista de Fray Luis: identifica lo infinito "absolutamente" con lo infinito "en la índole de ente"; sólo lo que es infinito en entidad es propia y absolutamente infinito. El ser o exisitir (esse), constitutivo formal del ente según la doctrina tomista,

distintos hombres. Lo mismo vale para otros modos de traducir ratio como "noción" o "concepto". Por ejemplo, cuando Tomás de Aquino dice que todo bien o fin tiene la ratio de apetecible, no está hablando del concepto subjetivo de "fin" o de "bien", sino de la realidad de las cosas que son buenas o fines. Evidentemente, es muy significativo que muchos escolásticos, para designar características objetivas o incluso esencias, usaran un sustantivo - ratio - conectado etimológicamente con la facultad racional; pero eso no debe llevar a equívocos. Más aun: muchas veces, en un mismo párrafo, los autores escolásticos pasan de modo casi inadvertido del sentido de ratio como concepto subjetivo al sentido de ratio como característica o esencia real u objetiva de lo pensado. Esta ambigüedad del uso del término ratio y su consiguiente dificultad para ser traducido, en mi opinión, son sólo el reflejo de uno de los temas centrales de la filosofía occidental, a saber, la dificultad de coordinar la referencia intrínseca e inmediata del pensamiento al ser y a la realidad - a lo "objetivo", al menos -, por un lado, con el carácter activo y productivo del pensar. Creo que, según los diversos contextos y pensadores, el término ratio puede traducirse alternativamente como ratio, "noción", "nota", "concepto", "índole", "carácter", "esencia" y hasta "naturaleza". En el contexto de esta discusión de Fray Luis con Escoto, me ha parecido adecuado traducirla por "índole", que no tiene un cariz ni demasiado subjetivo ni demasiado comprometido con un, llamémoslo así, objetivismo "realista".

27 Escoto no ignora la diferencia entre la infinitud de la línea, por ejemplo, y la infinitud de las perfecciones absolutas. Cf. DUNS ESCOTO. Ord. I, d. 8, p. 1, q. 3, n. 119 (Vat. IV, p. 210-211).

28 Si sólo la segunda es infinitud simpliciter, es claro que la primera es sólo secundum quid.

${ }^{29}$ Ibid. 
encierra en sí todas las demás "índoles" o "perfecciones"; en la índole de ente todas las demás perfecciones pueden unificarse y coexistir en simplicidad. Dice Fray Luis:

Y los atributos divinos son infinitos de este modo, porque, por ejemplo, la sabiduría de Dios no es infinita sólo en el género de la sabiduría, sino que también es de entidad infinita, a saber, de la misma entidad infinita que es la misma esencia divina. Así, hablando con verdad, la sabiduría de Dios incluye en su razón formal todas las naturalezas de todos los demás atributos y, así, la sabiduría de Dios no es de la misma naturaleza que la sabiduría que hay en las criaturas, y en esto difieren santo Tomás y Escoto. ${ }^{30}$

Las múltiples perfecciones de Dios se unifican en un tertium en el que todas coinciden: la perfección del ser. Para más claridad, se puede reformular así el razonamiento de Fray Luis: la sabiduría en Dios se identifica con el ser infinito. Ahora bien, el ser infinito se identifica con toda otra perfección. Luego, la sabiduría en Dios se identifica con toda otra perfección. Por otra parte, es muy importante, como se verá, el hecho de que la base para comprender esta unificación simple es posible reconocerla ya, en cierto modo, en el ámbito de lo creado; ya en el campo de lo experimentable y comprensible por el ser humano en esta vida se hace presente una perfección que reúne en sí misma a toda otra perfección, la del ser mismo, pues "todas las perfecciones pertenecen a la perfección del ser". ${ }^{31}$

\section{¿Hay verdadera diferencia en este punto entre Escoto y Tomás de Aquino?}

Afirma Fray Luis, en el texto arriba citado, que "en esto difieren Santo Tomás y Escoto". Sin embargo, algunos de sus propios maestros en la Universidad de Salamanca habían defendido que, en la cuestión de la distinción de los atributos divinos, la diferencia entre Tomás de Aquino y Escoto era sólo de nombre. ${ }^{32}$ Fray Luis alude a ellos y, seguramente, a otros que les hacían eco en su propio tiempo, con la expresión "ciertos tomistas". ${ }^{33}$ A mi juicio, el hecho de que Fray Luis entre en esta fina cuestión y tome partido, en este punto, en contra de la actitud conciliadora

30 DE LEÓN, F. Op. cit., p. 84-85.

31 Cf. TOMÁS DE AQUINO. Summa theologiae I q. 4, a. 2: "Omnium perfectiones pertinent ad perfectionem essendi".

32 Cf. CANO, M. Adnotationes in Primam Partem Divi Thomae, Biblioteca de la Universidad de Salamanca, Ms. 58, f. 40v. (En ORREGO, S. Op. cit., "Apéndice”, n. 469).

33 "Propter haec argumenta quidam thomistae dicunt et concedunt nomine tantum differre Divus Thomas et Scotus, inter distinctionem formalem et fundamentalem vel, ut quidam ex thomistis dicunt, distinctionem rationis ratiocinatae". DE LEÓN, F. Op. cit., p. 86-89. 
de sus antecesores en las cátedras salmantinas, es un claro indicio de su verdadero interés por el pensamiento escolástico. ${ }^{34}$

Fray Luis sintetiza los argumentos a favor del acuerdo entre Tomás de Aquino y Escoto señalando pasajes en que el Aquinate parece admitir que la distinción de los atributos es, en cierto modo, previa a la acción del intelecto. Pero es preciso advertir algo que Fray Luis no menciona, pero que no es versosímil que ignorara: el modo en que Escoto salva la simplicidad divina, habiendo afirmado la distinción formal de los atributos divinos como previa a la acción del intelecto, también se apoya en la infinitud que esos atributos tienen en Dios, lo que sería un motivo adicional para afirmar el acuerdo entre el Tomás y Escoto. En efecto, sostiene Escoto que, por ejemplo, la sabiduría en Dios se identifica con los demás atributos justamente porque es infinita; y lo infinito, por ser tal, es idéntico con todo lo que hay en aquello de lo que se predica. ${ }^{35}$

Fray Luis cita uno de los principales textos de santo Tomás que podrían aducirse para afirmar la identidad de su posición con la de Escoto: In I Sent. d. 2, q. 1, a. 2, que reproduzco con cierta extensión, porque es importante para clarificar finalmente la posición de Fray Luis y el porqué de su rechazo de la tesis de Escoto:

Y porque cada uno de ellos [sc., de los atributos] está en Dios según su razón más verdadera, y la razón de la sabiduría no es la razón de la bondad en cuanto tal, se sigue que son diversos en cuanto a la razón, no sólo por parte de quien razona, sino por parte de la propiedad de la realidad misma. Y de ahí deriva el que Él no sea una causa totalmente equívoca de las cosas, pues de acuerdo con su forma produce efectos semejantes, no unívocamente, sino análogamente, tal como de su sabiduría deriva toda otra sabiduría, y lo mismo sobre los demás atributos, según la doctrina de Dionisio. Por eso, Él mismo es la forma ejemplar de las cosas, no sólo en cuanto a aquello que está en su sabiduría, a saber, según las razones ideales, sino también en cuanto a aquello que está en su naturaleza, a saber, los atributos. Sin embargo, algunos dicen que estos atributos no difieren entre sí más que de acuerdo a las cosas que connotan en las criaturas. Pero esto no puede ser, primero, porque la causa no recibe nada del efecto, sino a la inversa, de manera que Dios no es llamado sabio porque la sabiduría procede de él, sino que más bien la realidad creada es llamada sabia en cuanto que imita la sabiduría divina; segundo, porque desde la eternidad, sin existir las criaturas, e incluso si éstas nunca hubiesen existido, fue verdadero decir que es sabio, bueno y cosas semejantes. Y no se significa lo mismo por uno que por otro como se significa lo mismo mediante sinónimos. ${ }^{36}$

34 No debe olvidarse que una de las acusaciones que llevaron a Fray Luis a las cárceles de la inquisición fue la de despreciar la teología escolástica (Cf. BARRIENTOS, J. Fray Luis de León y la Universidad de Salamanca. Madrid: Ediciones Escurialenses, 1996, p. 457) y muchos de los estudiosos del siglo XX del pensamiento del agustino avalan de algún modo ese parecer. Por eso hago esta observación.

35 Cf. DUNS ESCOTO. Ord. I, d. 8, p. 1, q. 4, n. 220 (Vat. IV, p. 275).

36 TOMÁS DE AQUINO. In I Sent. d. 8, q. 1, a. 2. 
Según esto, aludiendo también a otros pasajes de Tomás de Aquino ${ }^{37}$ y de Cayetano, afirma Fray Luis:

Así como Escoto afirma en los atributos de Dios una distinción formal antes de la operación del entendimiento, así santo Tomás y nosotros decimos que hay una distinción fundamental antes de toda operación del entendimiento, que parece ser lo mismo que sostiene Escoto. ${ }^{38}$

También acepta Fray Luis, siguiendo a Cayetano, que entre los atributos divinos, antes de la operación del entendimiento, hay una distinción virtual, pero no actual. ${ }^{39} \mathrm{Al}$ parecer, todos los autores citados hacen lo mismo: deben aceptar que la pluralidad de atributos es, en cierto modo, "objetiva", previa a la acción de nuestro entendimiento, para que el predicarlos de Dios no sea una pura repetición de lo mismo, y que, al predicarlos, hablamos verdaderamente de Dios. Y puesto que Dios es simple, esa pluralidad o distinción no puede ser real en el sentido propio de la palabra. A esto mismo parecen obedecer las expresiones "distinción formal", "fundamental", "virtual" o de "razón razonada" que Fray Luis también menciona -: son "objetivas" - esto es, apuntan primeramente a "lo razonado" y no "al razonante" -, mas no propia y plenamente "reales". Así lo entendieron los maestros de Fray Luis en Salamanca, como se vio, pero Fray Luis, con fuerza, sostiene que "sin duda lo contrario es verdadero, a saber, que hay una máxima diferencia entre Escoto y santo Tomás". ${ }^{40}$

¿Por qué Fray Luis se opone, en este caso, a la tesis de Escoto, a quien sigue contra Tomás en otras cuestiones más relevantes? A primera vista, la objeción de Fray Luis apunta que el Sutil introduce una división real en Dios, como queda claro por el siguiente texto:

Debe advertirse, a partir de santo Tomás, Opúsculo 72 , q. 4 y q. $5,^{41}$ que algo en la realidad puede corresponder a diversos conceptos de dos modos. De

37 TOMÁS DE AQUINO. S. Th. I, q. 13, a. 4. Apunta Fray Luis que Cayetano, comentando ese pasaje de la Summa theologiae, "dice que Dios es 'muchas razones', mas no de modo subjetivo, como si tuviera en sí mismo muchos conceptos de las cosas que conoce, sino que es muchas razones de modo objetivo". DE LEÓN, L. Op. cit., p. 86-87.

${ }^{38}$ DE LEÓN, L. Op. cit., p. 86-87.

39 Cf. CAYETANO (TOMÁS DE VIO). In De ente et essentia Divi Thomae Aquinatis commentaria (c. 6, q. 13) Roma: Marietti, 1934, p. 183.

40 DE LEÓN, L. Op. cit., p. 88-89.

${ }^{41}$ Se trata del texto espurio De concordantiis dictorum sancti Thomae, elaborado a partir de textos varios de Tomás de Aquino y publicado en Opuscula Sancti Thomae. Venecia, 1498, 320v-321r. Lo fundamental del pasaje citado por Fray Luis y de su solución a la cuestión se encuentra en TOMÁS DE AQUINO. In I Sent. d. 2, q. 1, a. 3. Este artículo del Comentario a las Sentencias del Aquinate no se incluía en el original leído en la Universidad de París, sino que se añadió posteriormente a partir del segundo comentario al mismo libro que Tomás de Aquino dio en Roma. Cf. http://www.corpusthomisticum.org/snp10023.html, "nota ad textum"; DONDAINE, A. 1930-1933. ID. 1938. 
un modo, cuando en la realidad misma se encuentran diversas naturalezas sobre las que se fundan diversos conceptos, de modo que una misma realidad corresponda a un concepto y no otro, o de modo que una misma realidad se exprese mediante un único concepto y otra mediante otro concepto, como es claro en el hombre blanco y en el músico; y tal diversidad de realidades establece una composición real en la misma. Y así se imagina Escoto que los atributos divinos son muchos, diversos entre sí, de modo que a los conceptos que poseemos sobre la bondad y la sabiduría de Dios correspondan, por parte de la realidad, en Dios, dos razones como si fueran realidades, de las cuales una se determina mediante un concepto y otra mediante otro. ${ }^{42}$

Sin embargo, no creo plausible que Fray Luis ignorara el empeño, muy rico en matices, con el que Escoto procura conciliar su distinción formalis ex natura rei aplicada a los atributos divinos con la absoluta simplicidad de Dios. ${ }^{43}$ Debe reconocerse, además, que todas las objeciones de Fray Luis a la tesis de Escoto, que en este trabajo no puedo recoger ni analizar, son expresamente discutidas in extenso por el mismo Escoto. ¿No era más sencillo interpretar la distinción formalis ex natura rei como una distinción de razón, equivalente a la "virtual" o "fundamental" de la escuela tomista? Pues este paso parece permitido por la ambigüedad - al menos aparente - de la mencionada distinción en el sistema de Escoto y, además, parece obligado hacerlo así, desde el momento en que Escoto afirma la absoluta simplicidad de Dios.

\section{¿Expresan los atributos la naturaleza misma de Dios? Verdadera diferencia de Fray Luis y Escoto}

Por eso, parece más plausible buscar la raíz de la divergencia entre Fray Luis y Escoto en otras expresiones que sí son abiertamente opuestas entre ambos pensadores y en las que se reflejan orientaciones de fondo presentes en las obras tanto académicas como exegéticas y literarias de Fray Luis, aunque no sea factible, en este breve espacio, discutir la correcta interpretación de los textos de ambos pensadores ni exponerlos en todo su desarrollo. Me limitaré, por ende, a lo que estimo más significativo.

En los textos de Fray Luis, que en este punto sigue en todo a Tomás de Aquino, se afirma expresamente que la causa de que las perfecciones que se predican de Dios y de las criaturas no sean totalmente equívocas, sino análogas, radica en que hay dependencia y cierta

42 DE LEÓN, L. Op. cit., p. 88-89.

43 Duns Escoto dedica expresamente a este tema una extensa cuestión: "Quaero utrum cum simplicitate divina possit stare aliquo modo distinctio perfectionum essentialium praecedens aliquo modo omnem actus intellectus". Ord. I, d. 8, p. 1, q. 4. Los editores, en el título de la cuestión, omiten la significativa expresión aliquo modo de la formulación de Escoto. 
semejanza entre, por ejemplo, la sabiduría divina y la sabiduría creada. En este contexto, el concepto expresa la realidad de aquello a lo que se atribuye: perfectamente, cuando los predicamos de las criaturas, e imperfectamente, cuando los predicamos de Dios. ${ }^{44}$ En esta concepción de la predicación, se puede decir que toda diversidad o semejanza intrínseca en la realidad va seguida necesariamente de una diversidad o semejanza en los conceptos que se predican directamente de ella.

Ahora bien, puesto que Escoto afirma una identidad no sólo análoga sino unívoca entre los conceptos que predicamos de Dios y de las criaturas, podría parecer que afirma una mayor semejanza entre Dios y las criaturas; pero la verdad parece ser precisamente la contraria. Escoto no ignora la infinita diferencia entre Dios y la criatura. Luego, si afirma que los conceptos que se predican de ambos son unívocos, esto sólo puede admitirse a condición de que dichos conceptos no expresen verdadera y directamente la esencia misma de Dios. Me parece de una importancia capital el siguiente texto del Sutil. Él mismo propone la siguiente objeción contra la posibilidad de que haya conceptos comunes a Dios y la criatura:

Además, tercero: las cosas primeramente diversas no coinciden en nada. Dios es primeramente diverso respecto de cualquier criatura; de lo contrario, habría algo en lo cual coincidiría y algo en lo cual diferiría y, así, no sería absolutamente simple. Por lo tanto, Dios no coincide en nada con la criatura y, así, tampoco coincide con ella en algún concepto común. ${ }^{45}$

Esta objeción supone la concepción de la predicación ya descrita, presente en Tomás y Fray Luis. Pues bien, la respuesta de Escoto apunta justamente a negar ese modo de correspondencia entre el concepto y la realidad de la que se predica:

A lo tercero: quedará claro en el artículo 3 [de la misma cuestión 3] 'que Dios y la criatura no son primeramente diversos en los conceptos'; pero son primeramente diversos en la realidad, porque no coinciden en ninguna

44 Cf. DE LEÓN, L. Op. cit., p. 94-97: “Segunda conclusión: estos nombres comunes dichos de Dios y de las criaturas no se dicen por completo equívocamente, sino análogamente. La primera parte de la conclusión es de santo Tomás en los lugares citados, y se prueba, porque estos nombres se subordinan a un único concepto formal. Luego, no se dicen de un modo puramente equívoco. Además, las cosas que se significan por un nombre puramente equívoco no poseen ningún orden entre sí ni ninguna semejanza en cuanto son significadas por aquel nombre. Pero aquello que en Dios y en las criaturas se significa con el nombre de "sabiduría" posee un orden y una semejanza entre sí, como es claro, pues la sabiduría creada es cierta participación y semejanza con la ciencia increada; luego".

45 DUNS ESCOTO. Ord. I, d. 8, p. 1, q. 3, n. 47 (Vat. IV, p.172): "Item, tertio sic: primo diversa in nullo conveniunt; Deus est primo diversus a quacumque creatura, alioquin haberet quo conveniret et quo differret, et ita non esset simpliciter simplex; ergo, Deus in nullo convenit cum creatura, et ita nec in aliquo conceptu communi". 
realidad. - Y de qué modo puede haber un concepto común sin coincidencia real o en la realidad, se dirá luego. ${ }^{46}$

De esto modo, si puede haber conceptos comunes y unívocos a Dios y a las criaturas, es porque esos conceptos comunes no expresan directamente la esencia misma de Dios. Como consecuencia, queda enfatizada fuertemente la trascendencia de la divinidad en cuanto tal y su heterogeneidad respecto de todo lo creado. Glosando a Juan Damasceno, Escoto parece afirmar que los atributos divinos designan algo en Dios, pero sin alcanzar formalmente la misma naturaleza divina, sino algo derivado en cierto modo de ella. ${ }^{47}$ Retomando el mismo texto del Damasceno, afirma que la esencia de Dios en cuanto que es "esta" - es decir, la divinidad en cuanto tal -, no posee en sí formalmente esa multitud de perfecciones que son sus atributos, pues eso sería una contradicción, sino que los posee sólo de modo eminente y causal, al modo de una emanación. ${ }^{48}$

46 DUNS ESCOTO. Ibid., n. 82 (Vat. IV, p. 190): "Ad tertium patebit in tertio articulo 'quia Deus et creatura non sunt primo diversa in conceptibus'; sunt tamen primo diversa in realitate, quia in nulla realitate conveniunt, - et quomodo possit esse conceptus communis sine convenientia in re vel realitate, in sequentibus dicetur".

47 DUNS ESCOTO. Ibid., q. 4, n. 158 (Vat. IV, p. 230-1): "Contra: Damascenus, libro I cap. 4: 'Si iustum, si bonum, si quid tale dixeris, - non naturam dicis Dei, sed quae circa naturam' (De fide orthodoxa I c. 4; PG 94, 799). Dicis autem aliquid quod praecedit actum intellectus: ergo, ante omne opus et actus intellectus, est aliquid in Deo quod non est natura formaliter".

48 Por su importancia para la tesis que defiendo, cito in extenso: "Nota pro dicto Damasceni, quod 'pelagus perfectionum' uno modo potest intelligi pro continente actu et formaliter in se omnes perfectiones, sub propriis rationibus formalibus: sic nihil unum-formaliter est 'pelagus', quia contradictio est unicam rationem formalem continere actu tot rationes. Hoc ergo modo nihil est 'pelagus' nisi unum identice, quod est: 'Deus, sapiens, bonus, beatus', et cetera omnia huiusmodi. Hoc modo non accipit Damascenus 'pelagus'.

Alio modo potest intelligi aliquid unum formaliter, continens omnem perfectionem modo eminentissimo, quo possibile est omnes in uno contineri: ille autem est quod non tantum contineantur identice, propter infinitatem formalem continentis (sic enim quaelibet [sc. Attributorum] continet omnes), sed ultra, contineantur virtualiter, quasi in causa, - et adhuc, in aliquo ut prima causa a se continente, et universalissima, quia omnes continente. Hoc modo essentia 'haec' est 'pelagus', quia in qualibet multitudine oportet stare ad aliquod omnino primum; in hac nihil est omnino primum nisi 'haec' essentia, ideo ipsa non tantum est formaliter infinita, sed virtualiter continens alias: nec tantum aliquas (sicut forte intellectus continet sapientiam et intelligere, et voluntas caritatem et diligere), sed omnes, nec ab alio virtute alterius continens, sed a se. Itaque, habet infinitatem formaliter et primariam, tam scilicet a se quam respecto omnium, universaliter causalem et virtualiter contentivam, - et ita 'pelagus', ita continens omnes sicut possunt eminenter in uno - formaliter aliquo contineri. Omnia flumina intrant in mare, unde exeunt revertuntur (Eccl. 1, 7)". DUNS ESCOTO. Ibid., nn. 199-200 (Vat. IV, p. 264-266). 
Aquí está la divergencia fundamental con la concepción de Fray Luis, quien también procura salvar la trascendencia e incognoscibilidad de Dios en sí mismo, pero, al mismo tiempo, sosteniendo que hay semejanzas verdaderas entre Dios mismo, esto es, lo que existe en él formalmente - la infinidad de sus perfecciones - y las criaturas. Al concebir los atributos divinos, concebimos algo de Dios en sí mismo, procurando no negar su infinita distancia. ${ }^{49}$ Según esta doctrina, Dios en cuanto tal es comunicable y participable ad extra; no perfectamente, pero verdaderamente. A esto obedece la tensa formulación de la analogía, en la que se incluyen expresiones que, por un lado, no están como tales en el Aquinate, y que, por otro lado, constituyen abiertas negaciones de lo sostenido por Escoto. ${ }^{50}$

\section{Conclusión: relevancia de la filosofía de luisiana de los atributos en el conjunto de su pensamiento}

En definitiva, sólo se puede aceptar la univocidad de los conceptos que atribuimos a las criaturas y a Dios en la medida en que se niega de algún modo que lo significado por esos conceptos existe formalmente en la divinidad en cuanto tal, de modo que ésta queda siempre en su pura trascendencia, más allá de todo lo que podemos concebir. Se afirma la

49 DE LEÓN, L. Op. cit., p. 88-89: “De otro modo puede corresponder algo en la realidad a diversos conceptos, no porque en la realidad haya una diversidad de razones y naturalezas, sino porque hay una sola naturaleza que es infinita realmente, de modo que mediante un solo concepto no puede concebirse en toda su plenitud, sino que excede toda concepción y posee en sí todo lo que de ella se concibe, como un amor infinito, [etc.]. Y de este tipo es la naturaleza divina, que, siendo única y simple, corresponde a diversos conceptos, diversidad que no está sólo en el que razona, sino también en la cosa misma, la cual, aunque no posea muchas realidades, posee el oficio (vicem) de muchas. Y así difieren mucho Escoto y santo Tomás".

50 DE LEÓN, L. Op. cit., p. 94-95: "Lo segundo que debe advertirse es que esta índole de sabiduría que significamos con un solo nombre y un solo concepto, concebimos que realmente está en Dios y en las criaturas a la vez, pero de modos diferentes, pues, primero, de un modo está en Dios y de otro en las criaturas, ya que en las criaturas está como accidente, mientras que en Dios es la misma sustancia de Dios. Segundo, no sólo está en Dios de otro modo, sino que ella misma es de una índole muy distinta que en las criaturas, porque, primero, la sabiduría en Dios posee perfectamente todos los grados de la sabiduría; más aún, es la misma sabiduría fontal, de la que deriva la que hay en las criaturas, pues la que está en las criaturas es una participación de ella y como una imagen de la sabiduría de Dios. Luego, es muy inferior y mucho más imperfecta. Además, la sabiduría creada es sólo sabiduría, mientras que la sabiduría que está en Dios no sólo es la sabiduría suprema, sino una sabiduría que es intrínseca y formalmente bondad, justicia, divinidad y cualquier otra cosa que se predica de Dios, de tal modo que si pudiéramos asignar la verdadera definición de la sabiduría divina, en aquella definición deberían incluirse todas las demás cosas". Cf. la tesis contraria en DUNS ESCOTO. Op. cit., nn. 192-4 (Vat. IV, p. 261-262). 
divinidad como absolutamente trascendente, pero su comunicabilidad se hace, por lo menos, problemática. Por la misma razón, si se afirma que los conceptos que atribuimos a las criaturas y a Dios expresan en cierto modo algo que está verdadera y formalmente en la divinidad en cuanto tal, de manera que se afirma en cierto modo la comunicabilidad y expresabilidad de la divinidad en el ámbito de lo creado, se hace obligado afirmar que aquellos conceptos no se predican unívocamente. Se afirma la divinidad como comunicable, pero parece restringirse el sentido de su absoluta trascendencia. Ésta segunda es la opción seguida por Fray Luis, y es de capital importancia para todas sus obras. Cuando lo oigamos hablar sobre "el Bien", "la Paz" o "la Unidad", celebrándolas en la música o la Naturaleza, sabremos que, al referirse a esas Ideas, como lo hacía Platón, está apuntando al corazón mismo de Dios, como se aprecia en el siguiente pasaje de De los nombres de Cristo:

Y la propia y verdadera sabiduría del hombre es saber mucho de Christo, y a la verdad es la más alta y más divina sabiduría de todas; porque entenderle a él es entender todos los tesoros de la sabiduría de Dios, que, como dize S. Pablo (Col 2, 2-3), están en él encerrados; y es entender el infinito amor que Dios tiene a los hombres, y la magestad de su grandeza, y el abysmo de sus consejos sin suelo, y de su fuerça invencible el poder inmenso, con las demás grandezas y perfecciones que moran en Dios, y se descubren y resplandecen más que en ninguna otra parte, en el mysterio de Christo. Las quales perfectiones todas, o gran parte dellas, se entenderán si entendiéremos la fuerça y significación de los nombres que el Espíritu Sancto le da en la Divina Escriptura; porque son estos nombres como unas cifras breves en que Dios, maravillosamente, encerró todo lo que acerca desto el humano entendimiento puede entender y le conviene que entienda. ${ }^{51}$

Es claro que el tema tratado merecería una elaboración mucho más matizada y extensa, como es claro por la extensión que recibe en las obras mismas de los autores mencionados en el presente trabajo. Aquí, sólo pretendo haber mostrado su sentido e importancia en el pensamiento de Fray Luis de León y, desde esta perspectiva limitada, mostrar que no hay dos "Luises de León", sino sólo uno, de pensamiento coherente, inseparablemente escolástico, platónico, humanista y místico.

51 DE LEÓN, L. De los nombres de Cristo. Ed. de Cristóbal Cuevas. $5^{\mathrm{a}}$ ed. Madrid: Cátedra, 1986, p. 147 (otrografía del original). Nótese que Fray Luis, en esta célebre obra, se propone tratar sólo de los nombres que le convienen a Cristo en cuanto hombre. En este mismo sentido, es de notar cómo, cerrando el libro, al tratar del nombre Iesus, advierte que en el original hebreo de este nombre, Iehosuah se incluyen todas las letras del "Tetragrama Sagrado" y se le añaden dos consonantes que hacen pronunciable y comprensible el nombre divino. Cf. Ibid., p. 623-624. 


\section{Bibliografía}

BARRIENTOS, J. Fray Luis de León y la Universidad de Salamanca. Madrid: Ediciones Escurialenses, 1996.

BELTRÁN DE HEREDIA, B. "Valor doctrinal de las lecturas de Báñez". Miscelánea Beltrán de Heredia, v. III, Salamanca, 1972.

BOLAND, V. Ideas in God according to Saint Thomas Aquinas: sources and synthesis. Leiden: E. J. Brill, 1996.

CANO, M. Adnotationes in Primam Partem Divi Thomae, Biblioteca de la Universidad de Salamanca, Ms. 58, f. 40v. In: ORREGO, S. La actualidad del ser en la primera escuela de Salamanca. Con lecciones inéditas de Vitoria, Soto y Cano. Pamplona: Eunsa, 2004.

CAYETANO (TOMÁS DE VIO). In De ente et essentia Divi Thomae Aquinatis commentaria. Roma: Marietti, 1934.

DE LEÓN, L. Dios y su imagen en el hombre. Lecciones inéditas sobre el libro I de las Sentencias (1570). Edición de Santiago Orrego. Pamplona: Eunsa, 2008.

. De los nombres de Cristo. Ed. de Cristóbal Cuevas. 5a ed. Madrid: Cátedra, 1986.

DE SOTO, D. In Porphyrii Isagogen ac Aristotelis Categorias (...) absolutissima commentaria. Venecia, 1587.

DONDAINE, A. "Saint Thomas et la dispute des attributs divins (I Sent., d. 2, a. 3). Authenticité et origine". Archivum Fratrum Praedicatorum 8 (1938), p. 253-262.

"Saint Thomas a-t-il disputé à Rome la question des 'attributs divins'? (I Sent., d. 2, q. 1, a. 3)". Bulletin Thomiste. Notes et communications 3 (1930-1933), p. 171-182.

DURANDO (Durand de Saint Pourçain), In Petri Lombardi Sententias Theologicas Commentariorum libri IIII. Venetiis: Ex Typographia Guerræa, 1571 (Edición facsímil de Ridgewood, New Jersey (EE.UU.): The Gregg Press Incorporated, 1964), 16va-20va.

HOENEN, M. "Propter dicta Augustini. Die metaphysische Bedeutung der mittelalterlichen Ideenlehre". Recherches de Théologie et Philosophie Médiévales, 64/2 (1997), p. 245-262.

JUAN DUNS ESCOTO. Lectura in librum primum Sententiarum. In: Ioannis Duns Scoti Opera Omnia vol. XVII, Civitas Vaticana: Typis Polyglottis Vaticanis 1966.

. Ordinatio I, d. 8. In: Ioannis Duns Scoti Opera Omnia vol. IV, Civitas Vaticana: Typis Polyglottis Vaticanis 1956.

NOONE, T. "La distinction formelle dans l'ecole Scotiste; Jean Duns Scot et la metaphysique classique". Revue des Sciences Philosophiques et Theologiques 83/1 (1999), p. 53-72.

OCKHAM, G. Scriptum in primum librum Sententiarum Ordinatio d. 2, q. 2. In: Opera philosophica et theologica. Opera theologica vol. II. New York: St. Bonaventure, 1970, p. 50-74.

ORREGO, S. "Recepción y transformación medieval de la doctrina platónica de las Ideas", en preparación.

. "Presentación: texto, contexto y criterios de edición". In: DE LEÓN, L. Dios y su imagen en el hombre. Lecciones inéditas sobre el libro I de las Sentencias (1570). Edición de Santiago Orrego. Pamplona: Eunsa, 2008. 
. La actualidad del ser en la primera escuela de Salamanca. Con lecciones inéditas de Vitoria, Soto y Cano. Pamplona: Eunsa, 2004.

POZO, C. Fuentes para la historia del método teológico en la Escuela de Salamanca. Granada: Facultad de Teología de Granada, 1962, vol. I.

PSEUDO DIONISIO AREOPAGITA. Los nombres de Dios. In: ID. Obras completas del pseudo Dionisio Areopagita. Madrid: BAC, 1990.

. La jerarquía celeste. In: ID. Obras completas del pseudo Dionisio Areopagita. Madrid: BAC, 1990.

TOMÁS DE AQUINO. Summa theologiae. http://www.corpusthomisticum.org

. Summa contra Gentiles. http://www.corpusthomisticum.org . In I Sententiarum. http://www.corpusthomisticum.org

UÑA JUÁREZ, A. "Guillermo de Ockham rechaza las Ideas. El giro filosófica de la modernidad y Platón". Anales del Seminario de Historia de la Filosofía 8 (1990-91), p. 9-40

VITORIA, F. Commentaria in Primam Partem Divi Thomae. Santander, Biblioteca Menéndez Pelayo, editado en POZO, C. Fuentes para la historia del método teológico en la Escuela de Salamanca. Granada: Facultad de Teología de Granada, 1962, vol. I. 